\title{
Information Sources for Trust Judgments in Managerial Relationships over Time: A Conceptual Analysis
}

\author{
Yung-Kuei Huang \\ University of Illinois at Urbana-Champaign \\ Linchi Kwok \\ Syracuse University
}

\begin{abstract}
This article presents a conceptual analysis concerning which factors influencing interpersonal trust are subject to change in their informational utility over the course of a managerial relationship and which factors are more likely to remain salient. Based on existing literature, the authors examine the utility of social categories, trustors' moods and emotions, third party influences, direct experiences, and shared perspectives as sources of trust-related data over time. A set of propositions are formulated to encourage future intellectual dialogues on trust development in vertical dyads and render a framework for empirical research in this area.
\end{abstract}

\section{Introduction}

Trust can have a significant impact on relational dynamics between leaders and followers in organizational settings. If leaders gain trust from followers, they can work with followers towards positive organizational outcomes; otherwise, disastrous results may follow (Burke, Sims, Lazzara, \& Salas, 2007). Recent research has confirmed that trust in vertical dyads can directly or indirectly lead to desirable organizational outcomes, such as improvements in job performance, organizational citizenship, job satisfaction, organizational commitment, cooperative behaviors, and goal and decision acceptance (e.g., Colquitt, Scott, \& LePine, 2007; Connell, Ferres, \& Travaglione, 2003; Dirks \& Ferrin, 2001, 2002). Given the important role trust plays within organizations, it has received a tremendous amount of attention from organizational scholars (Colquitt \& Rodell, 2011; Dirks \& Ferrin, 2002; Fulmer \& Gelfand, 2012).

Despite a substantial body of literature on trust, there are still important issues that require more in-depth inquiries (Colquitt, LePine, Zapata, \& Wild, 2011). For instance, a myth that trust grows over time has guided scholars to scrutinize the roles of relationship lengths in the dynamics of interpersonal trust (e.g., Dirks \& Ferrin, 2002; Levin, Whitener, \& Cross, 2006). While empirical evidence suggests no correlation between relationship lengths and levels of trust (Dirks \& Ferrin, 2002), Levin et al. (2006) argued that the relationship length matters only insofar as it may determine the relative importance of the bases on which individuals form their trust. Some informational cues may become more or less salient in dictating trust judgments as a relationship matures (Levin et al., 2006). Prior analyses, however, tended to focus on trustees' characteristics and dyadic interactions as information sources for trust judgments. There is a need to consider factors beyond trustees' characteristics and dyadic interactions when identifying how people use information sources for trust judgments over time. In addition, simply using relationship length as an index for understanding the formation of trust may overlook those factors whose relative importance for forming bonds of trust may not vary over time. The question, therefore, arises as to which factors that influence interpersonal trust are subject to change in their relative importance over the course of a manager-employee relationship and which factors are more likely to remain salient over time.

The aim of this paper is not to provide and examine an exhaustive list of trust factors. Rather, our intention is to extend and further develop arguments made by Levin et al. (2006) by providing a discussion on the relative importance of trust factors in vertical dyads over time at the individual and interpersonal levels of analysis. Our conceptual objective, based on a review of literature on attributes 
underpinning trust within a vertical dyad, is to highlight the dynamic roles of personal and interpersonal attributes in forming trust over the course of a manager-employee relationship. In our conceptual analysis, we recognize direct experiences through which two parties learn about each other as a meaningful element people may use to subjectively distinguish between a newer relationship and an older one. Assigning a specific objective criterion or a clear boundary of relationship lengths may fail to consider the context-dependent nature of trust dynamics and discourage future research endeavors. As such, we define newer relationships to be those characterized by fewer direct experiences within a given period of time and older relationships to be those characterized by more direct experiences.

We believe our analysis expands upon prior studies on trust by providing a conceptual discussion of the changing roles played by several prominent factors influencing trust within a vertical dyad over time. Specifically, we adopt an information processing perspective to conceptually evaluate the utility of five information sources for forming trust judgments, including social categories (i.e., demographic features), trustors' moods and emotions, third party influences, direct experiences, and shared perspectives. Despite growing interest in the roles of trustors' moods/emotions and third party influences in trust judgments, these two areas remain under-studied. In view of this, a more systematic analysis of how these two particular factors may serve as an input for trust judgments is also presented.

This paper begins with the definition of the trust construct, followed by a conceptual analysis of how five factors remain salient or undergo changes over time in terms of their information utility for trust judgments. We conclude with a discussion that highlights conceptual advances, limitations, future research directions, and practical implications.

\section{What is Trust?}

The construct of trust has been predominantly conceptualized as a psychological state in existing organizational literature (Hosmer, 1995; Kramer, 1999). However, scholars have not reached a consensus over the definition of trust. Some scholars viewed trust as confident, positive expectations about a trustee's intentions and actions (e.g., Boon \& Holmes, 1991; Cook \& Wall, 1980; Lewicki, McAllister, \& Bies, 1998; McAllister, 1995; Robinson, 1996; Whitener, Brodt, Korsgaard, \& Werner, 1998). Guided by this definition, scholars underscored the attitudinal and evaluative nature of trust (Jeffries, 2002; Robinson, 1996; Whitener et al., 1998). Other scholars defined trust as the willingness or intention of the trustor to be vulnerable (Mayer, Davis, \& Schoorman, 1995; Rousseau, Sitkin, Burt, \& Camerer, 1998). For example, Mayer et al. (1995) defined trust as "the willingness of a party to be vulnerable to the actions of another party based on the expectation that the other will perform a particular action important to the trustor, irrespective of the ability to monitor or control that other party" (p. 712).

We accept the definition of trust as confident, positive expectations about a trustee's intentions and actions. According to the theory of reasoned action (Ajzen \& Fishbein, 2005), a trustor's perceptions, beliefs, and attributions about the trustee directly guide him/her to evaluate expectations about the trustee (Whitener et al., 1998), and indirectly result in a higher or lower intention to be vulnerable. This logic is also supported in Dietz and Den Hartog's (2006) input-throughput-output model of the trust process. Therefore, given that the development of our conceptual analysis is rooted in an information processing view, the definition of trust as positive expectations may make our analysis more sensible.

We recognize that different definitions and measures of trust have been adopted in existing empirical studies. Mayer et al. (1995) identified a trustor's disposition to trust and a trustee's trustworthy characteristics as two prominent antecedents of trust. The use of this framework has drawn some scholars to consider trustors' perceived trustworthiness of the trustee as the focus in their empirical pursuits (e.g., Colquitt et al., 2011; Gill, Boies, Finegan, \& McNally, 2005; Lau, Lam, \& Salamon, 2008; Levin et al., 2006). While perceived trustworthiness is operationally defined as an evaluation of a trustee's characteristics, reflecting a trustor's expectations, Dietz and Den Hartog (2006) conceptualized perceived trustworthiness as a form of trust expectations. Therefore, we view perceived trustworthiness as trust expectations in our conceptual analysis. 


\section{Trust Parameters in Vertical Dyads over Time}

\section{Social Categories}

Without a rich history of interactions, individuals may rely on observable physical features or second-hand categorical data to form trust in a newer relationship (Levin et al., 2006), such as sex, race, ethnicity, age, generations, nationality, occupation, educational background, or even physical attractiveness. According to self-categorization theory, individuals have a tendency to classify others into social categories of salient demographic characteristics in order to reduce subjective uncertainty (Hogg \& Terry, 2000). This categorization process becomes a psychological mechanism that helps individuals cognitively segment, order, and systematize the social world (Ashforth \& Mael, 1989; Tajfel \& Turner, 1979). Category-based expectations are invoked when people have little time to assess one another as individuals (Meyerson, Weick, \& Kramer, 1996).

In the categorization process, stereotyping functions as an information-processing strategy that reserves considered cognitive efforts and allows the perceiver to rely on generalized beliefs about the attributes and behaviors of members of certain social groups (Hilton \& von Hippel, stereotypical beliefs underlying readily visible cues (e.g., demographic attributes), in turn, exert influence on the perceiver's impressions and judgments of trustworthiness, regardless of their positive or negative connotations. For example, people tend to perceive older workers as less 1996). Those productive, innovative, creative, motivated, ambitious, adaptable, receptive to new ideas and capable of learning, but more stable, reliable and truthful (Rosen \& Jerdee, 1976). Category-based information processing may enable individuals to assign trustworthy attributes to those who are members of groups with reputations for positive traits (Elsbach, 2004; McKnight, Cummings, \& Chervany, 1998). Employees with educational degrees received from certain prestigious institutions, for instance, may be perceived as more capable than graduates from less prestigious institutions. Such stereotypical beliefs may not only shape one's expectations of others, but also color perceptions of actual experiences, especially at the beginning of a dyadic relationship.

Although readily visible demographic cues or second-hand information about a particular individual provide an alternative information source for others to form impression and judgments, those categories need to be salient, or subjectively meaningful, to activate their impact on organizational members' attitudes and behaviors (Hogg \& Terry, 2000). Salience of social categories is contextdependent and can be manipulated. Self-categorization theory assumes category salience as a function of "an interaction between the 'relative accessibility' of the category within the perceiver's repertoire and the 'fit' between stimulus input and stored category specifications" (Oakes, Turner, \& Haslam, 1991, p. 126). Category accessibility refers to "the relative 'readiness' of a given category to become activated" (Oakes et al., 1991, p. 126). When a given category is valued as an important aspect of self-concept or is perceptually salient in the situation, high category accessibility occurs and the cognitive system is more likely to bring this category into active use (Hogg \& Terry, 2000). A strong fit between categories and social contexts occurs when categories can be used to describe situationally relevant similarities/dissimilarities, or when prototypical attributes associated with categories can account for context-specific behaviors. Therefore, a certain category may be more salient in some situations than others (e.g., being white in a racially diverse group versus in a racially homogeneous group with whites only, see Lau \& Murnighan, 1998, for a review).

In addition to category-based stereotypes, social identity theory and the similarity-attraction paradigm suggest that comparative demographic attributes in dyads can affect the individuals' evaluations of one another (Tsui \& Gutek, 1999). Social identity theory posits that the self-enhancement motive drives individuals to attribute more positive traits to ingroup members than to outgroup members in the categorization process (Hogg \& Terry, 2000; Tajfel \& Turner, 1979). Studies have concluded that the arbitrary grouping of individuals precipitates ingroup favoritism, in which they perceive members of their own group as more friendly, trustworthy, cooperative and honest than members of reference groups (Brewer, 1979; Brewer \& Silver, 1978). It is presumed within the similarity-attraction paradigm that greater perceived similarities between organizational members will increase interpersonal liking (Tsui \& 
O'Reilly, 1989). Accordingly, given that organizational members tend to see those with similar demographic attributes in a more positive light than those with dissimilar attributes (Tsui, Porter, \& Egan, 2002), interpersonal liking may encourage them to form trust in those who are demographically similar (Williams, 2001).

Scholarly work has empirically examined the effects of demographic similarity/dissimilarity on trust in vertical dyads, yielding some mixed findings. In a field study, Scott (1983) found that both male and female employees indicated higher levels of trust in the regional managers of the same sex than those of the opposite sex. Contrary to Scott's findings, Jeanquart-Baron (1993) found that male and female employees expressed higher levels of trust in their managers of the opposite sex than those of the same sex. Her post hoc explanation for this inconsistent result was that the female employees who participated in her study might not have been used to working for female managers, as most of them held secretarial positions. Male employees might also have a greater drive to progress professionally than female employees and, therefore, felt less secure in their subordinate positions. Jeanquart-Barone (1993) also examined the impacts of race on employees' trust in managers, suggesting that white and black employees expressed greater trust in their managers of the same race than those of different races.

Aside from methodological concerns regarding the validity of instruments, inconsistent results from preceding studies can be attributed to two major conceptual shortcomings. First, they failed to acknowledge that the relative importance of demographic cues available for trust judgments can change over the course of a relationship. In a recent study, Levin et al. (2006) found that awareness of the same gender had greater impacts on trust in a newer relationship than in an older relationship. Experimental studies (Lount, 2010; Tanis \& Postmes, 2005) indicate that, in the absence of cues to personal identity, participants act in accordance with group memberships displaying stronger trusting behavior toward ingroup members than outgroup members. Thus, it can be inferred that managers and employees are more likely to rest upon readily observable demographic cues to make inferences for trust judgments in a newer relationship than in an older relationship. Because those earlier studies failed to control for the length of dyadic relationships, the respondents might not necessarily have formed their trust based on readily observable demographic features of trustees. As individuals obtain more specific information about each other for inferences and attributions of behavioral intentions over the course of the relationship, the increased knowledge and greater familiarity may reduce the use of stereotypes in judging one another (Harrison, Price, \& Bell, 1998; Lau \& Murnighan, 1998; Levin et al., 2006). For instance, Harrison et al. (1998) found that time neutralized the effect of sex on group cohesion, while Levin et al. (2006) reported that the effect of sex similarity on trust declined over time.

Second, insomuch as a vertical dyad is characterized by power and status inequalities (Tsui et al., 2002), the relation between social categories and status implications must be recognized in the analysis of demographic similarity/dissimilarity within a vertical dyad. The assumption of similarity-based attraction, which accentuates positive effects associated with demographic similarity and negative effects associated with demographic dissimilarity, may not suffice to explain the dynamics within a vertical dyad (Goldberg, Riordan, \& Zhang, 2008; Lau et al., 2008; Tsui et al., 2002). Demographic similarity has been found to be a weak or insignificant predictor of employees' perceptions of their managers (e.g., Goldberg et al., 2008; Green, Anderson, \& Shivers, 1996; Lau et al., 2008). A single focus on similarity-based effects may overlook connotations of demographic differences for status inequalities. For example, societal norms in the past reinforced the submissive role of women. When this stereotype is perpetuated in the workplace, the placement of women in dominant positions may become less accepted, irrespective of their capabilities (Scott, 1983).

Expectation states theory argues that as the social system reinforces resource or status inequalities between categories of some social characteristics (e.g., sex, race, ethnicity, age), shared beliefs about greater "social worthiness and competence" ascribed to one category of the characteristic than another may arise (Correll \& Ridgeway, 2003, p. 32). By observing the distribution of demographic attributes throughout hierarchical levels in organizations, people may form normative expectations and beliefs that members of a certain social category achieve a certain role or status (Lawrence \& Tolbert, 2007). Such expectations and beliefs provide an individual with a frame of reference to infer whether certain 
demographic differences between job incumbents in vertical dyads meet expectations or lead to perceptions of status incongruence (Perry, Kulik, \& Zhou, 1999). Presumably, the sense of status incongruence may engender disruptive effects on attitudes or feelings towards the targeted individual (Vecchio, 1993).

Empirical evidence shows that the effect of perceived status congruence may conjoin or override similarity-based attraction in employees' perceptions of their managers or managers' perceptions of the employees. For example, Tsui et al. (2002) found that subordinates who were older than their supervisors received the lowest supervisor ratings of in-role and extra-role performance. Levin et al. (2006) found that since people normally expected that managers should be older than their employees, those who were in same-age or normative age pairings reported higher ratings of trust than those who had younger managers or older employees than their ages. In another study, Lau et al. (2008) reported that the effect of similarity-based attraction was not found in employees' trust in managers as far as education, tenure, and organizational rank were concerned. Their results suggested that normative differences in levels of education yielded a positive relation with trust. Though perceived status incongruence was not directly measured as a variable in the previous studies, we expect that perceived status incongruence may have negative impact on trust within a vertical dyad.

In summary, social categories may serve as an alternative information source for trust judgments. Drawing on relevant theories and accumulated evidence, we identified four factors that may determine the effects of social categories on trust. First, the salience of a social category observed on a trustee is a precondition for a trustor to view it as an information source. Second, the effect of social categories on trust may reside in the use of stereotyping as a cognitive shortcut, which may lead to a positive or negative expectation. Third, perceptions of social categories in dyadic contexts may evoke similaritybased attraction, which, in turn, may promote trust. Fourth, comparisons of social categories between members of a vertical dyad, in some cases, may lead to perceived status incongruence, which may hinder trust development. Therefore, we expect that when social categories are invoked as a trust-related information source, the valence of effects (positive vs. negative) social categories have on trust within a vertical dyad is a function of the salience of categories, context-relevant stereotypes, similarity-based attraction, and perceived status congruence/incongruence. In addition, we expect that informational utility of social categories for a trust judgment depends on time. As time provides opportunities for a manager and an employee to acquire better knowledge about each other, the effect of social categories on trust is very likely to decline over the course of a managerial relationship. Hence, we propose:

Proposition 1a: The valence of effects social categories have on trust formation within a vertical dyad is a function of the salience of categories, context-relevant stereotypes, similarity-based attraction, and a perception of category-based status congruence/incongruence.

Proposition 1b: The effect of social categories on trust within a vertical dyad is stronger in a newer relationship than in an older relationship.

\section{Emotions/Moods}

Not only does perceptual or communicated information afford trust judgments, but affective states may also come into play in trust formation (Schoorman, Mayer, \& Davis, 2007). Moods and emotions are affective states that signal people's ongoing experiences and reflect their state of being (Jones \& George, 1998). Moods are defined as "low-intensity, diffuse and relatively enduring affective states without a salient antecedent cause and therefore little cognitive content (e.g. feeling good or feeling bad)," while emotions are "more intense, short-lived and usually have a definite cause and clear cognitive content" (Forgas, 1992, p. 230). The experience of positive affective states may motivate people to approach and build connections with others, which in turn breeds trust (Williams, 2001). The experience of negative moods and intense negative emotions, such as anger, anxiety, and contempt, may cause people to refrain from interpersonal interactions, and may impede the opportunities to form trust. In our 
analysis, we primarily focus on how moods or emotions are used as information sources in forming trust expectations, particularly from an affect-as-information perspective (Schwarz, 2012; Schwarz \& Clore, 2003).

According to the affect-as-information approach, people's affective states can serve as a source of information (Schwarz, 2012) and, therefore, people may consult their pre-existing emotion or mood in forming judgments (Forgas, 1995). Drawing on accumulated evidence, Schwarz and his colleagues (Schwarz, Bless, Strack, Klump, Rittenauer-Schatka, \& Simons, 1991; Schwarz \& Clore, 1983, 2003) concluded that, when making evaluative judgments, people often implicitly ask themselves "how do I feel about this?" In response, they may misinterpret their current positive or negative affective state as a response to the object to be evaluated, if the informational value of the affective states for the judgment at hand is not discounted. In this sense, an affect-congruent influence on evaluations may arise in that a positive affective state may lead to a positive evaluation, whereas a negative affective state may result in a negative evaluation. Schwarz (2012) noted that the awareness of affective states may either eliminate affect-as-information effects if alternative information sources are available, or introduce a bias that may overcorrect the influence of affective states in the judgment.

Based on the premise derived from the affect-as-information approach that one's affective state may exert influence on the way he/she makes inferences and judgments, Jones and George (1998) proposed that "experiencing positive moods or emotions may cause one to have more positive perceptions of others and see the world through 'rose-colored glasses,' resulting in a heightened experience of trust in another person" (p. 534). In support of this prediction, studies have shown that positive moods result in more favorable first impressions of the targets than negative moods (e.g., Forgas \& Bower, 1987; Abele $\&$ Petzold, 1994; Forgas, 2011). Recently, Forgas and East (2008) found that people in a negative mood were more able to accurately detect lies than those in a positive mood, while those in a negative mood were more likely to view truthful communications with skepticism than those in a positive mood. It appeared that, as opposed to positive mood, negative mood might enhance detection sensitivity and evoke a more conservative criterion for accepting messages as truthful (Forgas \& East, 2008). In this sense, increased skepticism stemming from a bad mood may reduce trust in the target person. We, therefore, expect that a manager in a bad mood may demonstrate greater skepticism toward information communicated by his/her employee, thereby having lower trust in this particular employee. In contrast, a manager in a good mood may have a greater tendency to form positive and lenient inferences from observed cues, which promote this manager's trust in the employee. Likewise, mood can have a similar effect on employees' trust towards managers. Thus, we propose:

Proposition 2a: A bad mood will have a negative impact on trust within a vertical dyad; a good mood will have a positive impact on trust within a vertical dyad.

As far as emotions are concerned, findings from some experimental research have provided support for positive effects of specific positive emotions on trust and negative effects of specific negative emotions on trust (e.g., Dunn \& Schweitzer, 2005; Liu \& Wang, 2010). However, contrary to moods, which are more diffuse, less likely to be attributed to an immediate cause, and less easily detected (Fiedler, 2001; Forgas \& George, 2001), emotions are highly context-specific and, therefore, their cognitive and behavioral consequences tend to vary (Forgas \& East, 2008). Furthermore, distinct emotions of the same valence, such as anger, fear, sadness, and anxiety may not produce identical impacts on an evaluation of others, such as trust judgments (Clore \& Huntsinger, 2007; Lerner \& Keltner, 2000). For example, Dunn and Schweitzer (2005) found that angry people were less trusting than sad people. It may be premature to form a prediction for emotions and trust merely hinged on the assumption of affectcongruent effects, which contrasts the effects of positive versus negative emotions.

From an affect-as-information perspective, underlying cognitive-appraisal structures that differentiate emotional experiences in response to different events may have implications for understanding the informational value of different emotions for trust judgments (cf. Raghunathan \& Pham, 1999). Alternatively, theoretical and empirical evidence has suggested that the history of 
interactions may play a role in shaping informational utility of moods or emotions for trust judgments within a vertical dyad. The following discussion centers on the relevance of the underlying appraisal patterns of emotions in dictating the effects of emotions on trust, as well as varying salience of moods/emotions as informational input for trust judgments over the course of a managerial relationship.

\section{Emotion Appraisal}

According to appraisal theorists (e.g., Ellsworth, \& Smith, 1988; Frijda, Kuipers, \& ter Schure, 1989; Roseman, Antoniou, \& Jose, 1996; Roseman, Spindel, \& Jose, 1990; Smith \& Ellsworth, 1985), emotions can be defined by a number of appraisal dimensions beyond the appraisal of valence (positive vs. negative). Appraisal dimensions such as agency (e.g., who is responsible for the situation?), controllability (e.g., can I affect the situation?), and certainty (e.g., how certain am I about what is going on and what will happen next?) provide meaningful distinctions among emotions (e.g., Ellsworth, \& Smith, 1988; Frijda et al., 1989; Roseman et al., 1996; Roseman et al., 1990; Smith \& Ellsworth, 1985). For example, anger is typically associated with the sense of certainty, individual control, and otherresponsibility; fear is typically associated with the sense of uncertainty, situational control, and situational-responsibility.

We argue that, because different emotions are characterized by different appraisal profiles, not all positive or negative emotions have effects on trust judgments. The appraisals of agency and certainty are used to illustrate this point. Schwarz (2012) posited that the impact of affective states on social judgments may depend on their perceived relevance to the judgment at hand, while elaborating when affect-asinformation effects may arise. When the target of a trust judgment is another person, it can be speculated that emotions caused by others may have stronger carryover effects on this unrelated trust judgment as opposed to emotions caused by the self or situations (Dunn \& Schweitzer, 2005). In contrasting the effects of anger (characterized by other-responsibility) versus guilt (characterized by self-responsibility), and the effects of gratitude (characterized by other-responsibility) versus pride (characterized by selfresponsibility), Dunn and Schweitzer (2005) found that participants in the anger condition reported lower trust in their acquaintances than did participants in the guilt condition, and participants in the gratitude condition reported higher trust in their acquaintances than did participants in the pride condition. More importantly, their analysis showed that other-responsibility mediated the relationship between participants' emotions and their trust in acquaintances. Similarly, we expect that the influence of emotions attributed to situations may be weaker on trust judgments compared to emotions caused by others. For example, an angry manager may find it easier to blame his/her anger, caused by someone else, on a target employee than a sad manager who just learned about his/her loss of a friend.

The appraisal of certainty may also determine the magnitude of emotions' effects on trust judgments. According to Tiedens and Linton (2001), emotions characterized by a sense of certainty may result in more heuristic processing than emotions characterized by a sense of uncertainty. Research has found that the experience of certainty-associated emotions, such as anger, disgust, and contentment increase reliance on the use of stereotypes in judgments, as opposed to uncertainty-associated emotions, such as worry, fear, sadness, and surprise (Bodenhausen, Sheppard, \& Kramer, 1994; Tiedens \& Linton, 2001). In this sense, a manager/employee who experiences certainty-associated emotions may be drawn to make inferences for a trust judgment about his/her employee/manager based on heuristic cues (e.g., stereotypes). Therefore, the trust judgment made by the manager/employee feeling certainty-associated emotions is more likely to incur biases than managers/employees feeling uncertainty-associated emotions.

Taken together, we expect that the appraisals of other responsibility and certainty are likely to enhance an emotion's informational relevance for evaluating trust-related information within a vertical dyad. Hence, we propose:

Proposition 2b: A trustor's emotional state caused by others and characterized by high certainty will have a stronger effect on trust within a vertical dyad than will an emotional state caused by self or situations and/or characterized by high uncertainty. 


\section{History of Interaction.}

Forgas's (1995; see also Forgas \& George, 2001) affect infusion model proposes that the relationship between affective states and judgments may depend on the type of cognitive processing strategy a person adopts when a judgment is performed. The level of familiarity with a trustee may further determine what cognitive processing strategy a trustor will use for trust judgments (Dunn \& Schweitzer, 2005). When a trustor has a long history with a trustee, the trustor tends to automatically associate the trustee with high or low levels of trust without retrieving specific information from memory to support or refute the judgment. This type of cognitive processing strategy is less likely to be influenced by affective states (Forgas, 1995; Forgas \& George, 2001). In contrast, when having ambiguous information or little history with a trustee, a trustor may rely on heuristic thinking (i.e., general knowledge structures) to infer a trust judgment (Dunn \& Schweitzer, 2005; Jones \& Skarlicki, 2005). According to the affect infusion model, affect-as-information effects on judgments are more evident when this heuristic processing strategy is used (Forgas, 1995; Forgas \& George, 2001). As a result of cognitive processing strategies for judgments as a function of prior knowledge, the magnitude of the effects of moods/emotions on trust judgments may be contingent upon history of interactions. Specifically, mood-related cues or emotion appraisal dimensions, such as the appraisals of agency and certainty, may exert a more substantial influence on trust judgments in the early stages of relationship development (cf. Fiedler, 2001; Learner \& Keltner, 2001). In cases where a manager has limited knowledge of an employee, this manager may attend to trustworthy characteristics of the employee at a superficial level, such as clean-cut looks versus filthy and disorganized looks, for his trust judgment. Mood or specific emotional states may amplify the effect of using such stereotypes on trust judgments.

The findings from Dunn and Schweitzer's (2005) study have provided support for the greater use of the heuristic processing strategy when evaluating unfamiliar acquaintances as opposed to when evaluating familiar acquaintances. Their study revealed that incidental emotions such as anger and gratitude appeared to produce greater impacts on trust in unfamiliar acquaintances than in familiar ones. Building on prior theoretical reasoning and empirical evidence, we expect that a newer managerial relationship may lead to a greater reliance on heuristic processing for trust judgments due to limited knowledge about the other person. Therefore, a trustor's mood or emotion is more likely to emerge as an informational source and color his/her trust judgment about the other in a newer managerial relationship than in an older one.

Proposition 2c: The effect of a trustor's moods/emotions on trust within a vertical dyad will diminish as the relationship matures.

\section{Third Party}

In organizations, a manager-employee dyad is rarely isolated from a social context (Ferrin, Dirks, $\&$ Shah, 2006). Relationships with other individuals surrounding a dyad may affect the trust that grows between its members (Burt \& Knez, 1995, 1996; Ferrin et al., 2006). The presence of third parties or social network ties provides a valuable alternative conduit of knowledge about the prospective trustee (Kramer, 1999). Third parties may afford knowledge for a manager/employee to form trust in an employee/manager without rich direct experience through a number of ways. First, organizational members are not reactive agents passively waiting for information (Grant \& Ashford, 2008), and thereby they may seek out trust related information through monitoring social context cues, such as the prospective trustee's interactions with others or others' perceptions of the trustee (e.g., Ferrin et al., 2006; Lau \& Liden, 2008; Jones \& Skarlicki, 2005). For example, if a new employee overhears other coworkers' discussion about their manager's fairness, then this employee might form a positive or negative expectation about the manager based on these social cues (Jones \& Skarlicki, 2005). In 
horizontal dyadic contexts, Lau and Liden (2008) found that coworkers tended to trust more in fellow coworkers who were trusted by the team leaders than in those who were less trusted by the leaders.

Second, given that a reputational information sharing system may be embedded in a broad network of third parties who may have communication ties with a trustor, a trustee, or both (Wong \& Boh, 2010), the trustor may receive or request trust related information through formal or informal communications with third parties (e.g., Burt \& Knez, 1995, 1996; Ellwardt, Wittek, \& Wielers, 2012b). Upon hire, a manager might already have some expectations for a new employee based on letters of recommendation. Another relevant situation is that an employee might acquire some knowledge about his/her recently assigned boss from someone who previously worked for this boss and who has a social connection with the focal employee. The results of Burt and Knez's $(1995,1996)$ network study showed that third parties had a tendency to only disclose partial information that was consistent with their perceptions of the relationship status between the two members of the dyad. Research also suggested that third parties tend to spread positive information about their friends and negative information about their rivals (Ellwardt, Labianca, \& Wittek, 2012a; Grosser, Lopez-Kidwell, Labianca, \& Ellwardt, 2012). As the trustee often has little control over what third parties would say about him/her, information directly communicated from third parties about him/her can be a double-edged sword in forming the trustor's expectations. According to Kurland and Pelled (2000) and Michelson, van Iterson, and Waddington (2010), evaluative information shared between the trustor and third parties about the absent trustee through informal communications can be referred to as gossip. We accept this definition because it includes the possibility of either positive or negative evaluations of the absent person, allowing us to portray its double-edged effects on trust in our analysis.

From a social information processing perspective, when evidence for judgment is ambiguous, individuals are inclined to communicate with others and derive meanings from the communication (Salancik \& Pfeffer, 1978). In a similar vein, due to limited personal knowledge for trust judgments in the early stage of managerial relationships, individuals may opt to rely on information directly or indirectly from third parties to supplement or verify knowledge from first-hand experiences (Ferrin et al., 2006). However, even with prior knowledge about the trustee, the trustor within a vertical dyad is still likely exposed to information communicated from a third party, which may be congruent or incongruent with existing knowledge a trustor has about the trustee. While gossip may serve to detect free-riding or selfishness within work groups (Feinberg, Willer, Stellar, \& Keltner, 2012; Kniffin \& Wilson, 2005), gossip about an employee's inconsistent behavior when he/ she is not under managerial supervision, may provide an alternative view about this employee that the manager could not observe from direct experience. Alternatively, Burt and Knez $(1995,1996)$ found that third parties diffused trust-related information directly via gossip among senior managers in a high-tech firm, regardless of the length of their relationships with the target colleagues. Moreover, their study confirmed the effects of gossip on trust. Drawing on a social information processing approach, it can be argued that organizational contexts are ripe with information directly provided by or social cues learned from third parties, on the basis of which members within a vertical dyad can learn about each other, no matter the length of shared history. As such, we expect that third parties may exert influence on trust within a vertical dyad at any stage of relationship development.

\section{Proposition 3a: As a relatively constant information source in a direct and/or indirect fashion, the influence of third parties on trust within a vertical dyad may remain salient over time.}

\section{Gossip}

Because of the prevalence of gossip in the workplace (Ellwardt et al., 2012a), we further discuss how gossip as a prominent third-party information source influences trust within a vertical dyad. As discussed earlier, third-party gossip can contain positive or negative information about the absent prospective trustee. Its evaluative connotation may either promote or undermine trust development within a relationship (Burt \& Knez, 1995, 1996; Kramer, 1999). Research has documented that people generally 
place more weight on negative information than on positive information in forming impressions and social judgments (Labianca \& Brass, 2006; Skowronski \& Carlston, 1989). One of the theoretical accounts for the asymmetrical effects of positive and negative information lies in the discrepancy between negative information regarding others and the information recipient's normative expectancy (Skowronski \& Carlston, 1989). It is assumed that people tend to embrace moderately positive expectations about others. While negative information deviates from the normative expectancy, such deviation receives greater attention and enhances its informative utility in impression formation. In this sense, negative gossip may outweigh positive gossip in forming trust within a vertical dyad. For example, negative gossip that contradicts a manager's own personal observations and perceptions of an employee's performance may influence, and in some cases diminish, the manager's trust and increase doubt. In line with this negative asymmetry phenomenon, Burt and $\operatorname{Knez}(1995,1996)$ found that while positive (or negative) third-party gossip reinforced trust (or distrust) in existing relationships, the amplification effect was greater for negative gossip than for positive gossip. Therefore, we expect that the detrimental effect of negative third-party gossip on trust formation may be stronger than the enhancing effect of positive thirdparty gossip.

Proposition 3b: Negative third-party gossip will have a greater impact on forming trust within a vertical dyad than positive third-party gossip.

From a gossip recipient's perspective, the acceptance of a gossip message, however, may depend on its credibility (Kurland \& Pelled, 2000). Credibility here means the extent to which the gossip is believed to be accurate and truthful (Kurland \& Pelled, 2000). If the gossiper is deemed as trustworthy, the gossip message is more likely to be perceived as credible. The perceived quality of the message characterized by convincing specifics may also enhance its credibility (Slater \& Rouner, 1996). Research generally supports that credibility of a message induces greater acceptance of the message and more persuasion toward what is being argued (Pornpitakpan, 2004). A lack of credibility in a gossip message is expected to incur doubt in the content of the message and, therefore, the message recipient is very likely to discount its informational utility.

In addition to message credibility, shared opinions by different third parties emerge as another factor that may determine the extent to which the story of a third party will be accepted (Ferrin et al., 2006). In an empirical study with a sample of 74 professional and administrative employees, Ferrin et al. (2006) found a positive relationship between an employee's trust in a coworker and the number of third parties who were perceived as trustworthy by the focal employee and who trusted the coworker. A recent network study revealed that the scapegoats within an organizational network were the primarily objects of negative gossip (Ellwardt et al., 2012a). If a new manager is assigned to supervise one of the scapegoats, the prevalence of negative opinions about that particular employee may frame this manager's impression, which in turn affects his/her trust in the employee in the early stage of the relationship. In contrast, inconsistent opinions from third parties about an employee may increase a newly assigned manager's uncertainty about this employee's trustworthiness.

\section{Proposition 3c: Message credibility and opinion consistency will moderate the effect of third- party gossip on the development of trust within a vertical dyad.}

\section{Direct Experiences}

When the length of a dyadic relationship grows, both the manager and the employee will have more meaningful interactions with each other and more opportunities to observe each other's behaviors. Repeated episodes of joint efforts and communication allow them to learn about each other's words and deeds (Nelson \& Cooprider, 1996). An employee's fulfillment of a manager's expectations, by accomplishing a series of assigned tasks or duties, proves his/her value in the exchange relationship, providing cues for the manager to make attributions (Dienesch \& Liden, 1986). Through a series of 
interactions, a manager is able to know in what area(s) an employee is competent and in what area(s) an employee is inexperienced; a manager may gain insights about the extent to which an employee tends to tell the truth, keep promises, or bear responsibility for his/her own actions (Tschannen-Moran \& Hoy, 2000).

Given the authority and power granted to managers, as well as their potential for exploiting employees, their responsibility and role in building trust in vertical dyads have been emphasized in the literature. Researchers have identified a voluminous number of managerial behaviors that may be perceived as trustworthy and foster the development of employee trust in managers (e.g., Bijlsma, \& van de Bunt, 2003; Burke et al., 2007; Caldwell \& Hayes, 2007; Caldwell, Hayes, \& Long, 2010; Dirks \& Ferrin, 2002; Whitener et al., 1998). Empirical findings have also disclosed how managerial behavior may violate or betray trust. Bies and Tripp (1996) identified some specific actions that might lead to a violation of trust in management, such as changing the rules "after the fact," breaking promises, lying, stealing ideas, disclosing private confidences, abusing subordinates, and making wrongful or unfair accusations. Over time, trust varies across different managerial relationships as a result of different interpersonal dynamics.

As suggested by a social exchange approach, direct experiences allow members within a dyad to develop trust based on observed behavioral characteristics (Lewicki, Tomlinson, \& Gillespie, 2006). The accumulation of knowledge based on a history of direct experiences increases the validity of knowledgebased attribution (Levin et al., 2006). Therefore, a manager and an employee may rely on more specific behavioral information than generalized expectancies, stereotypical beliefs, or heuristics to form trust in one another as they obtain greater knowledge over time. To some extent, they are more able to make rational, context-specific trust judgments over time. Research has generally confirmed the strong relationships between trustworthy characteristics and trust (e.g., Colquitt et al., 2007; Gill et al., 2005; Levin et al., 2006; Jeffries, 2002; Yakovleva, Reilly, \& Werko, 2010).

The incremental effect of direct experiences on trust, however, may not appear to be constant over time. The cross-sectional data from Levin et al.'s (2006) work revealed that the effects of observed trustworthy behaviors on trust were greatest in relationships that were neither very new nor very old but in-between, suggesting a somewhat inverted U-shaped relationship between trustworthy behaviors and trust. Although their data is not longitudinal, the reported pattern echoes different phases of trust development (Lewicki, \& Bunker, 1996). According to Lewicki and Bunker (1996), once both parties have pretty good knowledge about one another's behavioral consistency and reliability, they may be willing to advance to a further stage in their trust relationships characterized by mutual understanding and identification with the other's desires. Given that not many relationships can evolve into the advanced stage of trust development, the information utility of observed trustworthy behavior for assessing trust may decline over time if a trust relationship is primarily based on this source of knowledge and progresses into a stable status. In view of this, we expect that the effects of trustworthy behavior observed from prior direct experiences on trust within a vertical dyad are likely to form an inverted U-shaped relationship with time.

\section{Proposition 4: The effects of trustworthy behavior observed from direct experiences on trust} within a vertical dyad will form an inverted $U$-shaped relationship with time.

\section{Shared Perspectives}

The relationship of shared perspectives in terms of values, beliefs, vision, attitudes, and preferences with interpersonal trust development has been theoretically discussed (e.g., Doney, Cannon, \& Mullen, 1998; Lewicki \& Bunker, 1996; Sitkin \& Roth, 1993; Williams, 2001). Shared perspectives are likely to be established through having similar backgrounds and experiences amongst members of the same social categories, and/or via social learning and socialization processes, in which observations of behaviors, interpersonal interactions, and third party influences have taken place. A sense of identification 
with each other and interpersonal liking may evolve as a consequence of having shared perspectives (Lewicki \& Bunker, 1996) and, in turn, foster the development of trust.

Research has suggested that similarities in a wide spectrum of experiences, interests, preferences and beliefs derived from a shared demographic category may have a more enduring bearing on the development of trust than the simple sharing of demographic attributes (McAllister, 1995). For example, $\mathrm{Lau}, \mathrm{Liu}$ and $\mathrm{Fu}$ (2007) found that differences in age and education levels were negatively related to leader-member value congruence, which in turn mediated the particular relationship between education differences and employees' felt trust. Another study conducted by Zenger and Lawrence (1989) revealed that employees of similar age had a common language outside the workplace, which in turn directly facilitated the establishment of informal communication links and indirectly eased the channel for formal, technical communication. Thus, shared demographic attributes may provide a lens to understand shared perspectives even though the direct effects of social categories on trust may diminish over time.

With the accumulation of knowledge about the other party, one may develop expectations about the other's needs, attitudes, thoughts, and preferences and realize similarities and commonalities beyond the superficial attributes between the two parties (Lewicki \& Bunker, 1996). According to social learning theory (Bandura, 1977), individuals in organizations learn about desired attitudes and behaviors through observations as well as direct experiences. In this sense, shared identity, beliefs, attitudes, values, and norms within a vertical dyad may develop beyond the conscious knowledge of common grounds as a consequence of subtle social learning and socialization processes. Peers, supervisors, and networks are useful sources for learning about which beliefs, values, and conducts are expected and which are not tolerated. In order to be accepted as a member of work groups, an employee experiences assimilation (Moreland \& Levine, 2002) and internalization of the group values, beliefs, and visions into his/her schema and motive systems (Tyler, 1997).

An employee can also be influenced by his/her manager through observational learning, imitation, and identification (Brown, Treviño, \& Harrison, 2005). A manager can nurture a sense of shared identity and values, as well as elevate employees' interest in and commitment to an organization's vision by means of appropriate leadership behaviors, such as role modeling, articulating and communicating a vision, and providing individualized support (Den Hartog, Van Muijen, \& Koopman, 1997). A manager may utilize downward influence in developing shared perspectives within a vertical dyad, whereas upward influence from an employee may co-construct and account for the growth of the commonalities. It is noteworthy that, owing to the influence of the social environment, employees may be pressured to publicly express and verbally support values and goals espoused by a manager or work unit whether or not they are held internally (Meglino \& Ravlin, 1998). In this case, the manager may use information from a third party and observations of employees' actual behaviors to validate the existence of shared values and goals.

Shared perspectives in various domains enable dyadic members in a managerial relationship to better predict each other's behaviors, fostering more efficient coordination of actions (Meglino \& Ravlin, 1998). For example, shared values may increase the perceptions of integrity because it is believed that the other is likely to behave in accordance with shared values (Williams, 2001), whereas shared goals (Williams, 2001) or a shared identity (Bhattacharya, Devinney, and Pillutla, 1998) may increase the perceptions of benevolence because there is a belief that the other will look out for one's interest. Empirical evidence suggests that people report greater trust when others embrace similar values and outlooks (Gillespie \& Mann, 2004; Levin et al., 2006; Tsai \& Ghoshal, 1998), as well as communicate with a shared language (Levin et al., 2006). Moreover, Levin et al. (2006) concluded that the utility of shared perspectives as an information source for trust judgments is more important in older than in newer vertical dyads. Therefore, we propose:

Proposition 5a: The effect of shared perspectives on trust increases over the course of a managerial relationship. 
Proposition 5b: Shared perspectives partially mediate the relationships of trust with social categories, direct experiences and third party input.

\section{Discussion}

In reviewing the existing literature, we sought to provide a better understanding about the roles of social categories, trustors' moods and emotions, third party influences, direct experiences, and shared perspectives in forming trust within managerial relationships over time. Table 1 summarizes the relevance of these trust parameters for forming trust judgments in newer and older relationships. Of the selected trust parameters being discussed, our analysis argues that third parties may be the only factor whose influences on forming trust judgments remain salient over time. Furthermore, our analysis suggests that social categories and a trustor's moods/emotions may be of less relevance for forming trust in an older relationship as compared to a newer relationship; the information utility of direct experiences for trust judgments may form an inverted-U shaped pattern with time; the utility of shared perspectives as an information source for trust judgments may escalate over time.

Table 1. Relevance of Trust Parameters in Vertical Dyads over Time

\begin{tabular}{|c|c|c|}
\hline \multirow[t]{2}{*}{ Trust Parameters } & \multicolumn{2}{|c|}{ Relevance for Forming Trust Judgments } \\
\hline & Newer Relationships & Older Relationships \\
\hline \multicolumn{3}{|l|}{ Change Over Time } \\
\hline $\begin{array}{l}\text { - Social Categories } \\
\text { (Proposition 1b) }\end{array}$ & Salient & Weak \\
\hline $\begin{array}{l}\text { - Trustors' Moods and Emotions } \\
\text { (Proposition 2c) }\end{array}$ & Salient & Weak \\
\hline $\begin{array}{l}\text { - Direct Experiences } \\
\text { (Proposition 4) }\end{array}$ & Weak & Salient $\rightarrow$ Weak \\
\hline $\begin{array}{l}\text { - Shared Perspectives } \\
\text { (Proposition 5a) }\end{array}$ & Weak & Salient \\
\hline \multicolumn{3}{|l|}{$\underline{\text { Remain Salient Over Time }}$} \\
\hline $\begin{array}{l}\text { - Third Party Influence } \\
\text { (Proposition 3a) }\end{array}$ & Salient & Salient \\
\hline
\end{tabular}

Since individuals often struggle for a balance between objectivity and cognitive efficiency when making judgments, the accessibility of information sources over time dictates the way individuals in vertical dyads form judgments. The more knowledge about the characteristics of a given trustee based on observations over time, the less likely the trustor will form trust simply based on cognitive bias from categorization or moods/emotions.

The role of categorization in determining trust in organizational contexts has been theoretically and empirically examined (e.g., Elsbach, 2004; Levin et al., 2006; McKnight et al., 1998; Williams, 2001). Since our analysis focuses on managerial relationships rather than general interpersonal relationships in organizations, we went beyond stereotyping and similarity-based affect by recognizing and articulating the operation of status expectations based on social categories in forming trust judgments between managers and employees. A consideration of category-based expectations mirroring hierarchical mindsets in managerial relationships is required for future research on exploring how demographic attributes shape dynamics within a vertical dyad.

There is relatively scant discussion on the potential effects of trustors' affective states when processing trust-related information in managerial relationships. Schoorman et al. (2007) noted that the effects of moods/emotions on trust warrant further investigations. Our analysis illustrated the relevance of the valence of moods and appraisal dimensions of emotions in forming trust judgments within a vertical 
dyad, especially when the relationship is newer. A recent conceptual analysis presented by Wildman et al. (2012) simply focused on the effects of positive versus negative emotions on trust, but our analysis suggests that the effects of emotions on trust are more complicated than a positive versus negative distinction. Drawing on earlier work on emotions, we argue that, as opposed to other types of emotions, emotions caused by others and associated with a sense of certainty may exert greater influence on a trustor's trust judgment when he/she experiences such emotions. Admittedly, the influences of an individual's affective states in forming trust judgments can be a more complex and dynamic process than the ones proposed in this paper. It is still possible that one's moods or emotions may enhance or reduce trust at key points in managerial relationships beyond their effects on impression formation in earlier stages of the relationships. Not only are an individual's interpretations of present interactions susceptible to an individual's moods or emotions, but also the dynamics and quality of future interactions (Hareli \& Rafaeli, 2008). Thus, moods/emotions perhaps have far-reaching effects on trust development beyond their informational utility for trust judgments.

Contrary to affective states, shared perspectives as an antecedent to trust have captured more scholarly attention (e.g., Gillespie \& Mann, 2004; Levin et al., 2006; Tsai \& Ghoshal, 1998). Since the reliance of shared perspectives for developing trust depends on the length of relationships (Levin et al., 2006), it is expected that the availability of this information source is greater in an older rather than in a newer managerial relationship. In addition to its varying utility as trust-related data, we suggest that shared perspectives may mediate the relationships of trust with social categories, direct experiences, and third party influences. This implies that when it takes time to develop trust, shared perspectives may complement the utility of direct experiences for building trust and serve as a cornerstone that enables two parties to advance their relationship into a more intimate phase. It is a key ingredient that encourages two parties to invest their affective bonds in a trusting relationship (Lewicki \& Bunker, 1996).

Third party influences are the only trust parameter in our analysis that was proposed to generate relatively strong impacts on trust judgments over time. We identified the valence of gossip, the credibility of gossip messages, and the consistency of opinions as possible parameters that determine the utility of gossip in forming trust judgments. Meanwhile, it is noteworthy that gossip transmission processes can be rather complex in the workplace, dictating what information third parties may disclose to members in vertical dyads. The nature of relationships with third parties, such as friendship ties, required workflow ties, or enemies, (i.e., Ellwardt et al., 2012b; Grosser, Lopez-Kidwell, \& Labianca, 2010; Grosser et al., 2012) and political agendas surrounding vertical dyads may affect the flow or exchange of negative and/or positive gossip. Because these interactions may complicate the already complex hierarchical structures beneath managerial relationships, it may be worthwhile to inquire, for example, whether or not managers and employees are exposed to different types of gossip information about the other. Given the proliferation of social networking sites, we wonder how the use of those sites would affect gossip transmission processes and trust. The link between third party information transmission and trust calls for more in-depth elaboration and exploration. Traditional micro approaches to examining interpersonal trust tend to rest upon the attributes of the trustor, the attributes of the trustee, and the dyadic interactions when explaining formation of the trustor's expectations about the trustee's trustworthiness (e.g., Becerra \& Gupta, 2003). The inclusion of third party influences in the conceptual framework casts insightful light on the process of obtaining trust-related data for trust judgments in managerial relationships.

Given that this paper uses a limited set of trust variables to advance the understanding about the interplay between time and those variables, several limitations need to be acknowledged. Individuals are not socially isolated actors in the workplace (Kramer, 1991), insofar as the relationship between individuals' behavior and the surrounding social contexts can evolve as a circling loop. The development of trust is, in effect, subject to the context-embedded nature of the personal and interpersonal factors. The context-embedded nature should be explicitly addressed. In particular, power distance and interdependent structure inherent within a vertical dyad may predispose the development of trust towards a complex calculative process beyond the dynamics described in this paper (see Willemyns, Gallois, \& Callan, 2003). Likewise, the effects of macro-level parameters (e.g., organizational structure, organizational culture, organizational policies, demographic composition, and national culture) can be observed on the 
development of trust in vertical dyads across organizations. Future theoretical endeavors can seek to integrate these factors across different levels along with time into a conceptual framework, which will ultimately present a fuller picture of trust development. We proposed that the utility of trust parameters may remain salient or change over time. However, the time duration trust parameters require for changes in their informational utility may vary from parameter to parameter, from person to person, and from context to context. Based on the research questions and obtained data, research efforts must specify the time duration. As theoretical discussions on the antecedents to trust have been blooming, the configuration in the conceptual framework proposed in this paper requires validation from future empirical research, providing an alternative venue for future studies on trust in the context of managerial relationships.

\section{Practical Implications}

The analysis in this paper also has practical implications for building trust in managerial relationships. For instance, we proposed that social categories and a trustor's moods/emotions may be of less salience as information sources for trust judgments over the course of managerial relationships, but this does not mean these two factors are not important in trust development. Their impacts in the early stage of managerial relationships may shift interpersonal dynamics from one direction to another, which in turn dictates how a trust relationship may evolve. Our proposition concerning how social categories affect trust has implications for managing diversity issues in managerial relationships. For example, managers and organizations should be aware that perceived status incongruence might arise in some cases. To reduce the emergence of such a perception, organizations should emphasize and ensure that placement and promotion are truly based on individuals' competence and qualifications rather than based on certain social categories.

We proposed that trust may undergo changes with a trustor's mood and emotions of certain types. As the awareness of affective states can reduce their effects on judgments (Schwarz, 2012), managers and employees need to be aware of their emotions/moods. Individuals with high levels of emotional intelligence are more likely to have knowledge of their emotional/mood states and have capabilities of managing emotions/moods (Cooper, 1997; George, 2000). They know when to use their emotions/moods to enhance information processing and have positive influences on others. They also establish stronger relationships with others. Organizations should introduce emotional intelligence training programs to alleviate the effects of misattribution resulting from moods/emotions.

The important role of third-party influences in manager-employee trust merits managers' attention. The discussion on how gossip influences trust within a vertical dyad provides insight into managing interpersonal networks as an indirect way for promoting and maintaining trust. Some managers or organizations may view gossip as dysfunctional activities in the workplace (Ellwardt et al., 2012a; Grosser et al., 2010; Michelson et al., 2010). From a manager's perspective, it serves as a useful mechanism to detect free-riding and selfishness (Feinberg et al., 2012; Kniffin \& Wilson, 2005) and identify those who go beyond the call of duty. With a proper use of gossip as an information source, managers may have more comprehensive knowledge about who is trustworthy and who is not.

Last, our analysis highlighted the curvilinear utility of observed behavior from direct experiences over time and the mediating role of shared perspectives for forming trust judgments. Accordingly, managers should be aware that trustworthy behavior may not be sufficient to enhance trust substantially after a certain level of trust is established. If greater trust is desired, managers can consider the importance of shared perspectives by creating collective identity and shared goals, and looking out for the interest of their employees (Lewicki \& Bunker, 1996).

\section{References}

Abele, A., \& Petzold, P. (1994). How does mood operate in an impression formation task? An information integration approach. European Journal of Social Psychology, 24(1), 173-187. 
Ajzen, I., \& Fishbein, M. (2005). The influence of attitudes on behavior. In D. Albarracin, B. T. Johnson, \& M. P. Zanna (Eds.), The handbook of attitudes (pp. 173-222). Mahwah, NJ: Lawrence Erlbaum Associates.

Ashforth, B. E., \& Mael, F. (1989). Social identity theory and the organization. Academy of Management Review, 14(1), 20-39.

Bandura, A. (1977). Social learning theory. Englewood Cliffs, N.J.: Prentice-Hall.

Becerra, M., \& Gupta, A. K. (2003). Perceived trustworthiness within the organization: The moderating impact of communication frequency on trustor and trustee effects. Organization Science, 14(1), $32-44$.

Bhattacharya, R., Devinney, T., \& Pillutla, M. (1998). A formal model of trust based on outcomes. Academy of Management Review, 23(3), 459-473.

Bies, R. J., \& Tripp, T. M. (1996). Beyond distrust: "Getting even" and the need for revenge. In R. M. Kramer \& T. R. Tyler (Eds.), Trust in organizations: Frontiers of theory and research (pp. 246260). Thousand Oaks, CA: Sage.

Bijlsma, K. M., \& van de Bunt, G. G. (2003). Antecedents of trust in managers: A “bottom up" approach. Personnel Review, 32(5), 638-664.

Boon, S. D., \& Holmes, J. G. (1991). The dynamics of interpersonal trust: resolving uncertainty in the face of risk. In R. A. Hinde, \& J. Groebel (Eds), Cooperation and prosocial behavior (pp. 190211). Cambridge, MA: Cambridge University Press.

Bodenhausen, G. V., Sheppard, L. A., \& Kramer, G. P. (1994). Negative affect and social judgment: The differential impact of anger and sadness. European Journal of Social Psychology, 24, 45-62.

Brewer, M. B. (1979). In-group bias in the minimal intergroup situation: A cognitive-motivational analysis. Psychological Bulletin, 86(2), 302-324.

Brewer, M. B., \& Silver, M. (1978). Ingroup bias as a function of task characteristics. European Journal of Social Psychology, 8, 393-400.

Brown, M. E., Treviño, L. K., \& Harrison, D. A. (2005). Ethical leadership: A social learning perspective for construct development and testing. Organizational Behavior and Human Decision Processes, 97, 117-134.

Burke, C. S., Sims, D. E., Lazzara, E. H., \& Salas, E. (2007). Trust in leadership: A multi-level review and integration. Leadership Quarterly, 18, 606-632.

Burt, R. S., \& Knez, M. (1995). Kinds of third-party effects on trust. Rationality and Society, 7, 255-292.

Burt, R. S., \& Knez, M (1996). Trust and third-party gossip. In R. M. Kramer \& T. R. Tyler (Eds.), Trust in organizations: Frontiers of theory and research (pp. 68-89). Thousand Oaks, CA: Sage.

Caldwell, C., \& Hayes, L. A. (2007). Leadership, trustworthiness, and the mediating lens. Journal of Management Development, 26(3), 261-281.

Caldwell, C., Hayes, L. A., \& Long, D. T. (2010). Leadership, trustworthiness, and ethical stewardship. Journal of Business Ethics, 96(4), 497-512.

Clore, G. L., \& Huntsinger, J. R. (2007). How emotions inform judgment and regulate thought. Trends in Cognitive Sciences, 11(9), 393-399.

Colquitt, J. A., LePine, J. A., Zapata, C. P., \& Wild, R. E. (2011). Trust in typical and high-reliability context: Building and reacting to trust among firefighters. Academy of Management Journal, 54(5), 999-1015.

Colquitt, J. A., \& Rodell, J. B. (2011). Justice, trust, and trustworthiness: A longitudinal analysis integrating three theoretical perspectives. Academy of Management Journal, 54(6), 1183-1206.

Colquitt, J. A., Scott, B. A., \& LePine, J. A. (2007). Trust, trustworthiness, and trust propensity: A metaanalytic test of their unique relationships with risk taking and job performance. Journal of Applied Psychology, 92(4), 909-927.

Connell, J., Ferres, N., \& Travaglione, T. (2003). Engendering trust in manager-subordinate relationships: Predictors and outcomes. Personnel Review, 32(5), 569-687.

Cook, J., \& Wall, T. D. (1980). New work attitude measures of trust, organizational commitment, and personal need non-fulfillment. Journal of Occupational Psychology, 53(1) 39-52. 
Cooper, R. K. (1997). Applying emotional intelligence in the workplace. Training and Development, 51(12), 31-38.

Correll, S. J., \& Ridgeway, C. L. (2003). Expectation states theory. In J. Delamater (Ed.), Handbook of social psychology, (pp. 29-51). New York: Kluwer Academic/Plenum.

Den Hartog, D. N., Van Muijen, J. J., \& Koopman, P. L. (1997). Transactional versus transformational leadership: An analysis of the MLQ. Journal of Occupational and Organizational Psychology, 70(1), 19-34.

Dienesch, R. M., \& Liden, R. C. (1986). Leader-member exchange model of leadership: A critique and further development. Academy of Management Review, 11(3), 618-634.

Dietz, G., \& Den Hartog, D. (2006). Measuring trust inside organizations. Personnel Review, 35(5), 557588.

Dirks, K. T., \& Ferrin, D. L. (2001). The role of trust in organizational settings. Organization Science, 12(4), 450-467.

Dirks, K. T., \& Ferrin, D. L. (2002). Trust in leadership: Meta-analytic findings and implications for research and practice. Journal of Applied Psychology, 87(4), 611-628.

Doney, P., Cannon, J., \& Mullen, M. (1998). Understanding the influence of national culture on the development of trust. Academy of Management Review, 23(3), 601-621.

Dunn, J. R., \& Schweitzer, M. E. (2005). Feeling and believing: The influence of emotion on trust. Journal of Personality and Social Psychology, 88(5), 736-748.

Ellsworth, P. C., \& Smith, C. A. (1988). From appraisal to emotion: Differences among unpleasant feelings. Motivation and Emotion, 12, 271-308.

Ellwardt, L., Labianca, G., \& Wittek, R. (2012a). Who are the objects of positive and negative gossip at work? A social network perspective on workplace gossip. Social Networks, 34, 193-205.

Ellwardt, L., Wittek, R., \& Wielers, R. (2012b). Talking about the boss: Effects of generalized and interpersonal trust on workplace gossip. Group \& Organization Management, 37(4), 521-529.

Elsbach, K. D. (2004). Managing images of trustworthiness in organizations. In R. M. Kramer \& K. S. Cook (Eds.), Trust and distrust in organizations: Dilemmas and approaches (pp. 275-292). New York: Russell Sage Foundation.

Feinberg, M., Willer, R., Stellar, J., \& Keltner, D. (2012). The virtues of gossip: Reputational information sharing as prosocial behavior. Journal of Personality and Social Psychology, 102(5), 1015-1030.

Ferrin, D. L., Dirks, K. T., \& Shah, P. P. (2006). Direct and indirect effects of third-party relationships on interpersonal trust. Journal of Applied Psychology, 91(4), 870-883.

Fiedler, K. (2001). Affective influences on social information processing. In J. P. Forgas (Ed.), The handbook of affect and social cognition (pp. 163-185). Mahwah, NJ: Erlbaum.

Forgas, J. P. (1992). Affect in social judgments and decisions: A multiprocess model. In M. Zanna (Ed.), Advances in experimental social psychology (Vol. 25, pp. 227-275). San Diego, CA: Academic Press.

Forgas, J. P. (1995). Mood and judgment: The affect infusion model (AIM). Psychological Bulletin, $117(1), 39-66$.

Forgas, J. P. (2011). Can negative affect eliminate the power of first impressions? Affective influences on primacy and recency effects in impression formation. Journal of Experimental Social Psychology, $47(2), 425-429$.

Forgas, J. P., \& Bower, G. H. (1987). Mood effects on person-perception judgments. Journal of Personality and Social Psychology, 53, 53-60.

Forgas, J. P., \& East, R. (2008). On being happy and gullible: Mood effects on skepticism and the detection of deception. Journal of Experimental Social Psychology, 44, 1362-1367.

Forgas, J. P., \& George, J. M. (2001). Affective influences on judgments and behavior in organizations: An information processing perspective. Organizational Behavior and Human Decision Processes, 86(1), 3-34.

Frijda, N. H., Kuipers, P., \& ter Schure, E. (1989). Relations among emotion, appraisal, and emotional action readiness. Journal of Personality and Social Psychology, 57(2), 212-228. 
Fulmer, C. A., \& Gelfand, M. J. (2012). At what level (and in whom) we trust: Trust across multiple organizational levels. Journal of Management, 38(4), 1167-1230.

George, J. M. (2000). Emotions and leadership: The role of emotional intelligence. Human Relations, 53(8), 1027-1055.

Gill, H., Boies, K. Finegan, J. E., \& McNally, J. (2005). Antecedents of trust: Establishing a boundary condition for the relation between propensity to trust and intention to trust. Journal of Business and Psychology, 19(3), 287-302.

Gillespie, N. A., \& Mann, L. (2004). Transformational leadership and shared values: The building blocks of trust. Journal of Managerial Psychology, 19(6), 588-607.

Goldberg, C., Riordan, C. M., \& Zhang, L. (2008). Employees' perceptions of their leaders: Is being similar always better? Group \& Organization Management, 33(3), 330-355.

Grant, A. M., \& Ashford, S. J. (2008). The dynamics of proactivity at work. Research in Organizational Behavior, 28, 3-34.

Green, S. G., Anderson, S. E., \& Shivers, S. L. (1996). Demographic and organizational influences on leader-member exchange and related work attitudes. Organizational Behavior and Human Decision Processes, 36(2), 203-214.

Grosser, T. J., Lopez-Kidwell, V., \& Labianca, G. (2010). A social network analysis of positive and negative gossip in organizational life. Group \& Organization Management, 35(2), 177-212.

Grosser, T. J., Lopez-Kidwell, V., Labianca, G., \& Ellwardt, L. (2012). Hearing it through the grapevine: Positive and negative workplace gossip. Organizational Dynamics, 41, 52-61.

Hareli, S., \& Rafaeli, A. (2008). Emotion cycles: On the social influence of emotion in organizations. Research in Organizational Behavior, 28, 35-59.

Harrison, D. A., Price, K. H., \& Bell, M. P. (1998). Beyond relational demography: Time and the effects of surface- and deep-level diversity on work group cohesion. Academy of Management Journal, 41(1), 96-107.

Hilton, J. L., \& von Hippel, W. (1996). Stereotypes. Annual Review of Psychology, 47, 237-271.

Hogg, M. A., \& Terry, D. J. (2000). Social identity and self-categorization process in organizational contexts. Academy of Management Review, 25(1), 121-140.

Hosmer, L. T. (1995). Trust: The connecting link between organizational theory and ethics. Academy of Management Review, 20(2), 379-403.

Jeanquart-Barone, S. (1993). Trust differences between supervisors and subordinates: Examining the role of race and gender. Sex Roles, 29(1/2), 1-11.

Jeffries, F. L. (2002). Subjective norms, dispositional trust, and initial trust development. Journal of Behavioral and Applied Management, 3(2), 129-139.

Jones, D. A., \& Skarlicki, D. P. (2005). The effects of overhearing peers discuss an authority's fairness reputation on reactions to subsequent treatment. Journal of Applied Psychology, 90(2), 363-372.

Jones, G. R., \& George, J. M. (1998). The experience and evolution of trust: Implications for cooperation and teamwork. Academy of Management Review, 23(3), 531-546.

Kniffin, K. M., \& Wilson, D. S. (2005). Utilities of gossip across organizational levels: Multilevel selection, free-riders, and teams. Human Nature, 16(3), 278-292.

Kramer, R. M. (1991). Intergroup relations and organizational dilemmas: The role of categorization processes. Research in Organizational Behavior, 13, 191-228.

Kramer, R. M. (1999). Trust and distrust in organizations: Emerging perspectives, enduring questions. Annual Review of Psychology, 50, 569-598.

Kurland, N. B., \& Pelled, L. H. (2000). Passing the word: Toward a model of gossip and power in the workplace. Academy of Management Review, 25(2), 428-438.

Labianca, G., \& Brass, D. J. (2006). Exploring the social ledger: Negative relationships and negative asymmetry in social networks in organizations. Academy of Management Review, 31(3), 596-614.

Lau, D. C., Lam, L. W., \& Salamon, S. D. (2008). The impact of relational demographics on perceived managerial trustworthiness: Similarity or norms? Journal of Social Psychology, 148(2), 187-208. 
Lau, D. C., \& Liden, R. C. (2008). Antecedents of coworker trust: Leaders' blessings. Journal of Applied Psychology, 93(5), 1130-1138.

Lau, D. C., Liu, J., \& Fu, P. (2007). Feeling trusted by business leaders in China: Antecedents and the mediating role of value congruence. Asia Pacific Journal of Management, 24, 321-340.

Lau, D. C., \& Murnighan, J. K. (1998). Demographic diversity and faultlines: The compositional dynamics of organizational groups. Academy of Management Review, 23(2), 325-340.

Lawrence, B. S., \& Tolbert, P. S. (2007). Organizational demography and individual careers: Structure, norms and outcomes. In H. P. Gunz \& M. A. Peiperl (Eds.), Handbook of career studies (pp. 399421). Thousand Oaks, CA: Sage.

Levin, D. Z., Whitener, E. M., \& Cross, R. (2006). Perceived trustworthiness of knowledge sources: The moderating impact of relationship length. Journal of Applied Psychology, 91(5), 1163-1171.

Lerner, J. S., \& Keltner, D. (2000). Beyond valence: Toward a model of emotion-specific influences on judgment and choice. Cognition and Emotion, 14(4), 473-493.

Lewicki, R. J., \& Bunker, B. B. (1996). Developing and maintaining trust in work relationships. In R. Kramer \& T. R. Tyler (Eds.), Trust in organizations: Frontiers of theory and research (pp. 114139). Thousand Oaks, CA: Sage.

Lewicki, R. J., McAllister, D. J., \& Bies, R. J. (1998). Trust and distrust: New relationships and realities. Academy of Management Review, 23(3), 438-458.

Lewicki, R. J., Tomlinson, E. C., \& Gillespie, N. (2006). Models of interpersonal trust development: Theoretical approaches, empirical evidence, and future directions. Journal of Management, 32(6), 991-1022.

Liu, M., \& Wang, C. (2010). Explaining the influence of anger and compassion on negotiators' interaction goals: An assessment of trust and distrust as two distinct mediators. Communication Research, 37(4), 443-472.

Lount, R. B. Jr. (2010). The impact of positive mood on trust in interpersonal and intergroup interactions. Journal of Personality and Social Psychology, 98(3), 420-433.

Mayer, R. C., Davis, J. H., \& Schoorman, F. D. (1995). An integrative model of organizational trust. Academy of Management Review, 20(3), 709-734.

McAllister, D. J. (1995). Affect- and cognition-based trust as foundations for interpersonal cooperation in organizations. Academy of Management Journal, 38, 24-59.

McKnight, D. H., Cummings, L. L., \& Chervany, N. L. (1998). Initial trust formation in new organizational relationships. Academy of Management Review, 23(3), 473-490.

Meglino, B. M., \& Ravlin, E. C. (1998). Individual values in organizations: Concept, controversies, and research. Journal of Management, 24(3), 351-389.

Meyerson, D., Weick, K. E., \& Kramer, R. M. (1996). Swift trust and temporary groups. In R. Kramer \& T. R. Tyler (Eds.), Trust in organizations: Frontiers of theory and research (pp. 166-195). Thousand Oaks, CA: Sage.

Michelson, G., van Iterson, A., \& Waddington, K. (2010). Gossip in organizations: Contexts, consequences, and controversies. Group \& Organization Management, 35(4), 371-390.

Moreland, R. L., \& Levine, J. M. (2002). Socialization and trust in work groups. Group Processes \& Intergroup Relations, 5(3), 185-201.

Nelson, K. M., \& Cooprider, J. G. (1996). The contribution of shared knowledge to IS group performance. MIS Quarterly, 20(4), 409-432.

Oakes, P. J., Turner, J. C., \& Haslam, S. A. (1991). Perceiving people as group members: The role of fit in the salience of social categorizations. British Journal of Social Psychology, 30, 125-144.

Perry, E. L., Kulik, C. T., \& Zhou, J. (1999). A closer look at the effects of subordinate-supervisor age differences. Journal of Organizational Behavior, 20, 341-357.

Pornpitakpan, C. (2004). The persuasiveness of source credibility: A critical review of five decades' evidence. Journal of Applied Social Psychology, 34(2), 243-281. 
Raghunathan, R., \& Pham, M. T. (1999). All negative moods are not equal: Motivational influences on anxiety and sadness on decision making. Organizational Behavior and Human Decision Processes, 79(1), 56-77.

Robinson, S. L. (1996). Trust and breach of the psychological contract. Administrative Science Quarterly, 41, 574-599.

Roseman, I. J., Antonioiu, A. A., \& Jose, P. E. (1996). Appraisal determinants of emotions: Constructing a more accurate and comprehensive theory. Cognition and Emotion, 10(3), 241-277.

Roseman, I. J., Spindel, M. S., \& Jose, P. E. (1990). Appraisals of emotion-eliciting events: Testing a theory of discrete emotions. Journal of Personality and Social Psychology, 59(5), 899-915.

Rosen, B., \& Jerdee, T. H. (1976). The nature of job-related age stereotypes. Journal of Applied Psychology, 61(2), 180-183.

Rousseau, D. M., Sitkin, S. B., Burt, R. S., \& Camerer, C. (1998). Not so different after all: A crossdiscipline view of trust. Academy of Management Review, 23(3), 393-404.

Salancik, G. R., \& Pfeffer, J. (1978). A social information processing approach to job attitudes and task design. Administrative Science Quarterly, 23, 224-250.

Schoorman, F. D., Mayer, R. C., \& Davis, J. H. (2007). An integrative model of organizational trust: Past, present, and future. Academy of Management Review, 32(2), 344-354.

Schwarz. N. (2012). Feelings-as-information theory. In P. Van Lange, A. Kruglanski, \& E. T. Higgins (Eds.), Handbook of theories of social psychology (Vol. 1, pp. 289-309). London: Sage Publications.

Schwarz, N., Bless, H., Strack, F., Klump, G., Rittenauer-Schatka, H., \& Simons, A. (1991). Ease of retrieval as information: Another look at the availability heuristic. Journal of Personality and Social Psychology, 61(2), 195-202.

Schwarz, N., \& Clore, G. L. (1983). Mood, misattribution and judgments of well-being: Informative and directive functions of affective states. Journal of Personality and Social Psychology, 45, 513-523.

Schwarz, N., \& Clore, G. L. (2003). Mood as information: 20 years later. Psychological Inquiry, 14(3/4), 296-303.

Skowronski, J. J., \& Carlston, D. E. (1989). Negativity and extremity biases in impression formation: A review of explanations. Psychological Bulletin, 105(1), 131-142.

Slater, M. D., \& Rouner, D. (1996). How message evaluation and source attributes may influence credibility assessment and belief change. Journalism \& Mass Communication Quarterly, 73(4), 974-991.

Smith, C. A., \& Ellsworth, P. C. (1985). Patterns of cognitive appraisal in emotion. Journal of Personality and Social Psychology, 48(4), 813-838.

Scott, D. (1983). Trust differences between men and women in superior-subordinate relationships. Group and Organization Studies, 8(3), 319-336.

Sitkin, S. B., \& Roth, N. L. (1993). Explaining the limited effectiveness of legalistic "remedies" for trust/distrust. Organization Science, 4, 367-392.

Tajfel, H., \& Turner, J. C. (1979). An integrative theory of intergroup conflict. In W. G. Austin \& S. Worchel (Eds.), The social psychology of group relations (pp. 33-47). Monterey: Brooks-Cole.

Tanis, M., \& Postmes, T. (2005). A social identity approach to trust: Interpersonal perception, group membership and trusting behaviour. European Journal of Social Psychology, 35, 413-424.

Tiedens, L. Z., \& Linton, S. (2001). Judgment under emotional certainty and uncertainty: The effects of specific emotions on information processing. Journal of Personality and Social Psychology, 81(6), 973-988.

Tschannen-Moran, M., \& Hoy, W. K. (2000). A multidisciplinary analysis of the nature, meaning, and measurement of trust. Review of Educational Research, 70(4), 547-593.

Tsai, W., \& Ghoshal, S. (1998). Social capital and value creation: The role of intrafirm networks. Academy of Management Journal, 41(4), 464-476.

Tsui, A. S., \& Gutek, B. A. (1999). Demographic differences in organizations: Current research and future directions. Lanham, Maryland: Lexington Books. 
Tsui, A. S., \& O'Reilly, C. A. (1989). Beyond simple demographic effects: The importance of relational demography in superior-subordinate dyads. Academy of Management Journal, 32(2), 420-423.

Tsui, A. S., Porter, L. W., \& Egan, T. D. (2002). When both similarities and dissimilarities matter: Extending the concept of relational demography. Human Relations, 55(8), 899-929.

Tyler, T. R. (1997). The psychology of legitimacy: A relational perspective on voluntary deference to authorities. Personality and Social Psychology Review, 1, 323-345.

Vecchio, R. P. (1993). The impact of differences in subordinate and supervisor age on attitudes and performance. Psychology and Aging, 8(1), 112-119.

Whitener, E. M., Brodt, S. E., Korsgaard, M. A., \& Werner, J. M. (1998). Managers as initiators or trust: An exchange relationship framework for understanding managerial trustworthy behavior. Academy of Management Review, 23(3), 513-530.

Wildman, J. L., Shuffler, M. L., Lazzara, E. H., Fiore, S. M., Burke, C. S., Salas, E., \& Garven, S. (2012). Trust development in swift starting action teams: A multilevel framework. Group \& Organization Management, 37(2), 137-170.

Willemyns, M., Gallois, C., \& Callan, V. J. (2003). Trust me, I'm your boss: Trust and power in supervisor-supervisee communication. International Journal of Human Resource Management, $14,117-127$.

Williams, M. (2001). In whom we trust: Group membership as an affective context for trust development. Academy of Management Review, 26(3), 377-396.

Wong, S., \& Boh, W. F. (2010). Leveraging the ties of others to build a reputation for trustworthiness among peers. Academy of Management Journal, 53(1), 129-148.

Yakovleva, M., Reilly, R. R., \& Werko, R. (2010). Why do we trust? Moving beyond individual to dyadic perceptions. Journal of Applied Psychology, 95(1), 79-91.

Zenger, T. R., \& Lawrence, B. S. (1989). Organizational demography: The differential effects of age and tenure distributions on technical communication. Academy of Management Journal, 32(2), 353376. 